\title{
Simulation of Rutherford Backscattering Cross Section of Atoms
}

\author{
Salim H. Al-Shamma \\ Department of Physics / College of Education \\ University of Mosul
}

Received
$05 / 05 / 2010$

Accepted

14 / 09 / 2010

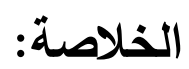

تعتبر تقنية رذرفورد للاستطارة الخلفية كأداة مه مة وفائقة في التحليل السطحي من بين

التقنيات الأخرى المستخدمة ـ تم في هذا البحث بناءٍ برنامج حاسوبي لدراسة تفصيلية للمعالم

المهمة في تقنية رذرفورد للاستطارة الخلفية مثل المعامل الحركي، المقاطع العرضية الخلفية،

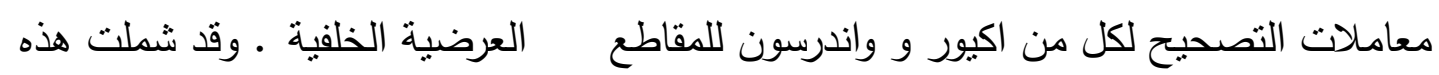

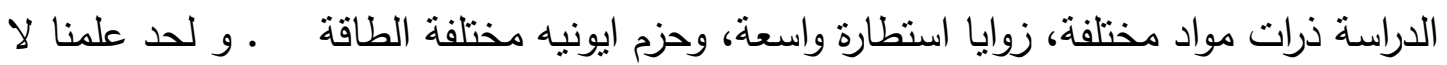
توجد نتائج عملية منوفرة لإجراء المقارنة على الحسابات النظرية الحالية.

\section{ABSTRACT:}

Rutherford backscattering spectrometry is considered as a very powerful tool in surface analysis among other various techniques employed. In this work a computer program had been built for detailed study of the important parameters that influence Rutherford backscattering spectrometry including the kinematic factor or ( $\mathrm{k}$ factor), mass resolution, Rutherford backscattering cross section, Andersen and L.Ecuyer correction factores.

The simulation had been carried out for different mass target atoms, scattering angles and ion energies. Most of the data obtained are not avaliable in the literature for comparison.

\section{Introduction:}

Rutherford backscattering spectrometry (RBS) is an established analytical technique and latterly has been become the most commonly used in the field of ion beam technique in material science $[1,2,3,4,5]$. 
Its power lies in speed of analysis, a completely quantitative, non destructive technique. In addition to measure the composition and thickness of thin films, mass and depth of target sample and good resolution for low mass element $[3,4]$.

RBS is very complementary or related techniques used for surface analysis, such as Auger electron spectroscopy (AES), X-ray fluorescence spectroscopy (XRF), X-ray photoelectron spectroscopy (XPS) and secondary ion mass spectroscopy (SIMS). [6, 7]

RBS is based on the electrical interaction between (ion-target) combination. RBS uses a high energy ion to examine the properties of the solid through ion backscattering technique. There are two main types of ion sources. Plasma and ion beam. The advantages of ion beam analytical method as there ease to use, non destructive and quantitative interpretation the experimental results. The application of RBS covers a wide range of branches of science such as geology, mineralogy, biology and medicine [3].

Overview of RBS yield data has been taking by researchers for various ion - target pair [8,9 and 10].

In this paper, a computer program had been built to simulate the important parameters in RBS, such as k factor, Rutherford backscattering cross section of atoms and L.Ecuyer and Andersen cross section correction factors.

\section{Theory:}

RBS technique involves bombarded a surface with a monochromatic beam of high energy of ions. Some of the ions are scattered from the target through an angle $(\theta)$. The scattering angle may vary from (0 to $\left.180^{\circ}\right)$.

In the inelastic recoil process, the ions may give recoil energy to the target atoms and then collected in a solid state detector. The detected ions are recorded as a function of an angle or energy.

In general, $\mathrm{H}$ and $\mathrm{He}$ ions are used of energies in the range of 100 $\mathrm{keV}$ to some $\mathrm{MeV}$.

\section{1- Kinematic of the elastic scattering ( $k$ factor):}

The $\mathrm{k}$ factor is defined as the energy of scattered ion (E) divided by the initial of ion energy (Eo) and is given by [6]

$$
\mathrm{K}=\frac{E}{E o}=\left[\frac{\left(M_{2}^{2}-M_{1}^{2} \sin ^{2} \theta\right)^{1 / 2}+M_{1} \cos \theta}{\left(M_{1}+M_{2}\right)}\right]^{2}
$$

Where $M_{1}$ and $M_{2}$ are the masses of incident ion projectile and target atom respectively.

$\mathrm{E}_{\mathrm{o}}$ and $\mathrm{E}$ are the energies of incident and scattered ions respectively. 
$\theta$ is the scattering angle.

The kinematic of the elastic scattering is shown in fig(1).

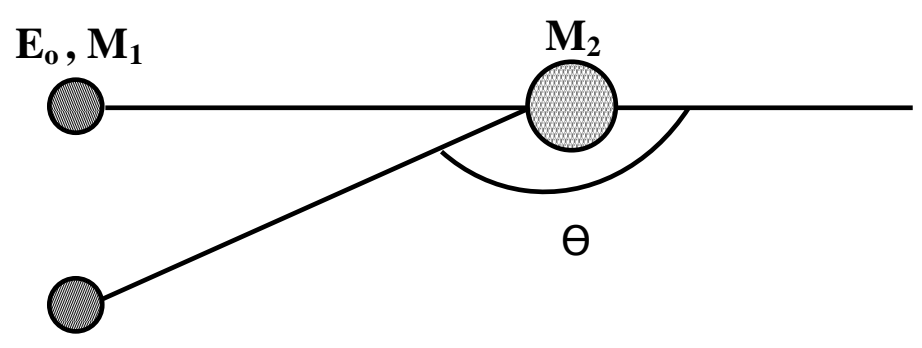

$E_{1}, M_{2}$

Fig (1): Schematic diagram of Rutherford backscattering

Inverse mass resolution: $\left(\frac{M_{2}}{\Delta M_{2}}\right)$

The inverse mass resolution is given by [11]

$\frac{M_{2}}{\Delta M_{2}}=\frac{E o}{\Delta E} x \frac{2 \mu\left(1-\mu^{2} \sin ^{2} \theta\right)^{1 / 2}}{(1+\mu)^{3}\left(1-\mu^{2} \sin ^{2} \theta\right)^{1 / 2}}\left(1+\mu-\cos \theta\left[\left(1-\mu^{2} \sin ^{2} \theta\right)^{1 / 2}+\mu \cos \theta\right]-\right.$

Where $\mu$ is the mass ratio: $\left(\frac{M_{1}}{M_{2}}\right)$

$\Delta \mathrm{M}_{2}$ is the mass difference

$\frac{E o}{\Delta E}$ is equal $10^{3}$

\section{Rutherford backscattering cross section: $\boldsymbol{\sigma}_{\text {Rth }}$}

The Rutherford backscattering cross section in the laboratory system is Given by (7)

$$
\frac{d \sigma}{d \Omega}(\mathrm{mb} / \mathrm{sr})=5.183743 \times 10^{6}\left(\frac{Z_{1} Z_{2}}{E(k e V)}\right)^{2} x \frac{\left(\left(M_{2}^{2}-M_{1}^{2} \sin ^{2} \theta\right)^{1 / 2}+M_{2} \cos \theta\right)^{2}}{M_{2} \sin ^{2} \theta\left(M_{2}^{2}-M_{1}^{2} \sin ^{2} \theta\right)^{1 / 2}}
$$

Where $\mathrm{Z}_{1}$ and $\mathrm{Z}_{2}$ are the nuclear charges of the incident ion and target atom

respectively.

\section{Andersen correction factor: $\left(\mathbf{F}_{\text {And }}\right)$}

The Andersen correction factor for Rutherford backscattering cross section is given by [7]

$\sigma=\mathrm{F}_{\text {And }} \sigma$ Rth

$\mathrm{F}_{\text {And }}=\left(\frac{\left(1+\frac{1}{2} \frac{E_{1}}{E_{C M}}\right)^{2}}{1+\frac{E_{1}}{E_{C M}}+\left(\frac{E_{1}}{2 E_{C M} \sin \theta_{C M} / 2}\right)^{2}}\right)$ 
Where $\mathrm{E}_{1}[\mathrm{keV}]=0.04573 \mathrm{Z}_{1} \mathrm{Z}_{2}\left(\mathrm{Z}_{1}{ }^{2 / 3}+\mathrm{Z}_{2}{ }^{2 / 3}\right)^{1 / 2}$

\section{Ecuyer correction factor: $F$}

Rutherford backscattering cross section at low energy is deviated from the actual cross section is caused by partial screening of the nuclear Charges surrounding both nuclei. For the scattering angle greater than $90^{\circ}$, The correction factor is given by [7]

$$
F=1-\frac{0.049 Z_{1} Z_{2}^{4 / 3}}{E_{C m}(k e V)} \text {-------- }
$$

\section{Results and Discussion:}

A computer program had been built to study

\section{1- k factor:}

Equation (1) had been used to show the $\mathrm{k}$ factor as a function of the scattering angle (in the laboratory system).This had been carried out for different target atoms such that (U, Bi, Cu, $\mathrm{Au}, \mathrm{W}, \mathrm{In}, \mathrm{Fe}, \mathrm{Ni}, \mathrm{Al}, \mathrm{Mg}$ and $\mathrm{F})$ and different $(\mathrm{H}, \mathrm{He}$ and $\mathrm{Bi}$ ) ion projectiles combinations.

$\mathrm{H}$ ion projectile is shown in Fig. (2), while for He ion projectile is shown in fig. (3) and for Be ion projectile is shown in Fig. (4).

One can observe from fig. (2) for the target atom of high atomic number such as ( $\mathrm{U}, \mathrm{Bi}$ ) when its bombarded with $\mathrm{H}$ ion, the $\mathrm{k}$ factor, shows a little changes with the scattering angle, while the $\mathrm{k}$ factor shows a cleared changes when the same atom is bombarded with ( $\mathrm{He}$ and $\mathrm{Be}$ ) ions as shown in Figs (3 and 4). While for other atoms with less atomic number, the $\mathrm{k}$ factor shows a drastic changes with the scattering angles as shown in

Figs(2, 3 and 4). This can be explained due to the recoil energy given to the nucleus by the incident ions.

One can conclude from the simulation that the $\mathrm{k}$ factor had a great dependence on the (target atom of low atomic numbers - ion) combinations with the scattering angles.

A further study had been done for $\mathrm{k}$ factor dependence on the scattering angles (in the center mass system) for selected target atoms $(\mathrm{Ni}, \mathrm{Al}, \mathrm{Mg}$ and $\mathrm{F}$ ) which was bombarded by $(\mathrm{H}, \mathrm{He}$ and $\mathrm{Be}$ ) ions combinations are shown in ( $a, b$ and $c$ ) of Fig. (5) respectively. A cleared difference can be seen if one compare with the (target - ion) combination in Fig. (5) with those of the same (target - ion) combinations in previous figures obtained in the laboratory system especially for large scattering angles. This is due to the difference in the changes in both (Lab. And C.M) systems.

The relation between the backscattering angle in both laboratory and center of mass systems is given by $\left(\theta_{c m}=\arcsin \left(\frac{m_{i o n}}{m_{t a \arg e t}} \sin \theta\right)+\theta\right)$ and shown 
in ( $a$ and $b$ ) of Fig.(6). This study had been made for selected target atoms $(\mathrm{Al}, \mathrm{Ti}$, and $\mathrm{Au})$ and $(\mathrm{He}$ and $\mathrm{Be})$ ions combinations. For $\mathrm{He}$ ion projectile as in Fig. $(6-a)$, the relation between the angles for (target ion) combinations seems nearly.

Similar while for Be ion as in Fig. $(6-b)$ for same (target - ion) combination shows a clear difference between the three sets of combinations. This is due to the recoil energy given to the target atom by ion projectile i.e due to type of ion projectile.

A polar plot had been obtained for $\mathrm{k}$ factor for a selected target atoms ( $\mathrm{U}, \mathrm{Cu}$ and $\mathrm{Au}$ ) through incident $(\mathrm{H}, \mathrm{He}$ and $\mathrm{Be}$ ) ion combinations as shown in ( $\mathrm{a}, \mathrm{b}$ and $\mathrm{c}$ ) of Fig (7) respectively. For $\mathrm{H}$ ion projectile as in Fig (7), the angular dependence of $\mathrm{k}$ factor for three target atoms (U, $\mathrm{Cu}, \mathrm{Fe}, \mathrm{Al}$ and $\mathrm{Au}$ )seems nearly symmetric, while for $\mathrm{He}$ ion projectile as in Fig. $(7-b)$, the angular distribution of $\mathrm{k}$ factor shows a symmetric. For $\mathrm{Be}$ ion projectile as in Fig. $(7-\mathrm{c})$, the drastic change for $\mathrm{k}$ factor distribution appeared due to the heavy Be ion projectile.

A further study had been performed for $\mathrm{k}$ factor as a function of target mass for incident $(\mathrm{H}, \mathrm{He}, \mathrm{Li}, \mathrm{Be}, \mathrm{O}, \mathrm{Si}, \mathrm{Cl}$, and $\mathrm{Ti}$ ) ions. This simulation was carried out at three scattering angles (120,150 and $\left.180^{\circ}\right)$ as in $\mathrm{a}, \mathrm{b}$ and $\mathrm{c}$ of Fig. (8) respectively. One can see from this figure that the $\mathrm{k}$ factor increased with increasing the target mass atoms for all incident projectiles and scattering angles. Then the $\mathrm{k}$ factor approaches nearly unity for large target mass and incident ion projectiles.

Fig. (9) shows a surface plot of $\mathrm{k}$ factor dependence on the mass ratio $\left(\mathrm{M}_{1} / \mathrm{M}_{2}\right)$ and on the scattering angles.

One can see from this figure that the $\mathrm{k}$ factor exhibits a uniform and constant value for relavent light elements, while for heavy projectiles, the k value changed drastically as shown in Fig.(10).

\section{2- Inverse mass resolution: $\left(\mathrm{M}_{2} / \Delta \mathrm{M}_{2}\right)$}

Equation (2) had been used for 3D plot of mass resolution dependence on the mass ratio $\left(\mathrm{M}_{1} / \mathrm{M}_{2}\right)$ and on the scattering angles for energy resolution $\left(\Delta \mathrm{E} / \mathrm{E}_{\mathrm{o}}=10^{-3}\right)$.

As shown in Fig.(11-a) that the mass resolution start from about 400 to 1000 when the mass ratio increased from zero to one and the scattering angle increased from $\left(180\right.$ to $\left.90^{\circ}\right)$. The dip appears at a scattering angle $90^{\circ}$ due to $(\cos \theta)$ in equation (2).

Fig. (11-b) is an extension to the Fig.(11-a) for the mass ratio greater than one. The mass resolution reaches the maximum value to about two for the scattering between $\left(0\right.$ and $\left.90^{\circ}\right)$ and then drastically dropped to the lower value and increased up going to infinity as shown in this figure. 


\section{3- Rutherford backscattering cross section:}

Equation (3) had been use for 3D plot of Rutherford differential cross section in terms of $\left(Z_{1}\right.$ and $\left.Z_{2}\right)$ dependence on the mass ratio $\left(\mathrm{M}_{2} / \mathrm{M}_{1}\right)$ and on the scattering angles $(\theta)$ as shown in Fig. (12). This simulation had been done for incident energy $(10 \mathrm{keV})$. One can observe from this figure that the differential cross section increased from $\left(10^{4}\right.$ to about $10{ }^{9} \mathrm{mb} / \mathrm{sr}$ ) when the mass ratio increased from (10 to 100) and the scattering angle appeared to be constant with a value $180^{\circ}$.

A further study had been performed for 3D plot of differential cross section interms of $\left(\mathrm{Z}_{1}\right.$ and $\left.\mathrm{Z}_{2}\right)$ dependence on the incident ion projectile and on the mass ratio $\left(\mathrm{M}_{2} / \mathrm{M}_{1}\right)$ for scattering angles $(120,150$ and $175^{\circ}$ ) as shown in a, b and c of Fig. (13). One can observe from this figure that the differential cross section is decreased with increasing the incident ion energy over the mass ratio $\left(\mathrm{M}_{2} / \mathrm{M}_{1}\right)$ for the scattering angles (120, 150 and $175^{\circ}$ ). In addition, the differential cross section at scattering angle $\left(120^{\circ}\right)$ is more than three times than at scattering angle $\left(150^{\circ}\right)$ and five times than that at scattering angle $\left(175^{\circ}\right)$.

\section{4- Andersen correction factor:}

Equation (4) had been used for a plot of Andersen correction factor for Rutherford cross section as a function of scattering angle $(\theta)$. for various incident ion energies. This was performed for two target atoms (U and $\mathrm{Au})$ through incident $(\mathrm{H}, \mathrm{He}$ and $\mathrm{Be})$ ions as shown in Fig.(14 and 15) respectively.

It appeared from these figures that for high incident energies, the Andersen correction factor is uniform and close to unity at scattering angles $\left(\theta>40^{\circ}\right)$ for the three set of

(target -ion) combinations. While for the incident energies (500, 250 and 100) $\mathrm{keV}$, the Andersen correction factor becomes to less than unity for all sets of (target-ion) combinations.

A further study had been done for a polar plot of Andersen correction factor for target gold bombarded by $(\mathrm{H}, \mathrm{He}$ and $\mathrm{Be})$ ion projectiles as in a, b and c of Fig. (16). As observed in Fig. (16- a) for (Au-H ion) combination, shows a divergent about eight degree on each side around the scattering angle equal to zero. This divergent depends on the kind of ion projectile. As can be seen from this figure that in case of incident $\mathrm{Be}$ ion, the divergent becomes more obvious for small scattering angles as in Fig. (16-c) in comparison with those of(b and a) of fig. (16). This can be explained due to the nuclear charges of (target -ion) combinations.

\section{5- L.Ecuyer correction factor:}

Equation (5) was used to plot L.Ecuyer correction factor for Rutherford backscattering cross section (screaning correction factor) as a function of incident ion energies as shown in a and b of Fig.(17).

This study had been done for targets ( $\mathrm{Ti}, \mathrm{Au}, \mathrm{Bi}$ and $\mathrm{U}$ ) atoms through incident $(\mathrm{H}$ and $\mathrm{He})$ ions. As can be observed from this figure 
that Ecuyer correction factor increased by increasing the incident ion energy and approach close to unity for all (target -ion) combinations., this will make the results easy to understand. One can conclude that this correction factor is Important at low incident energies and for heavy atoms and heavy ions.
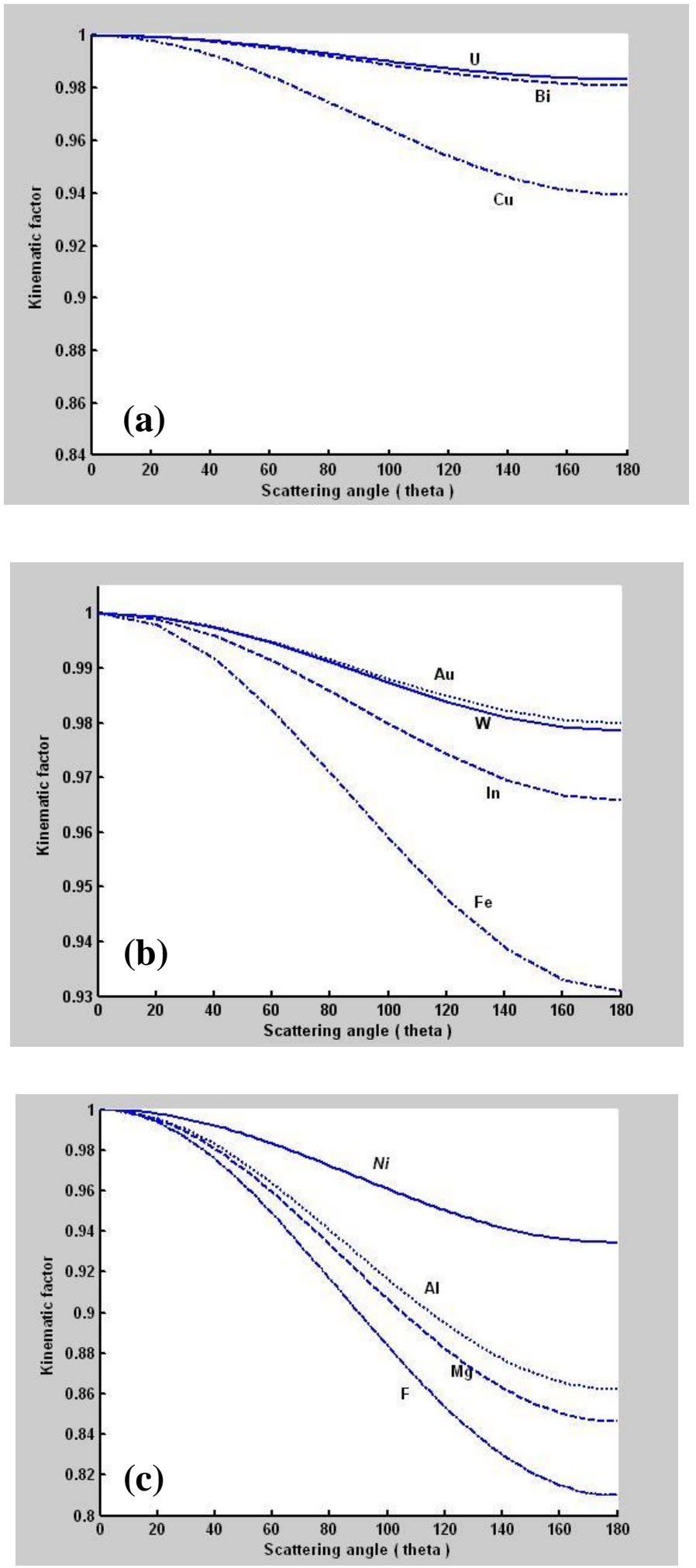

Fig (2): Kinematic factor as a function of scattering angle for different elements (incident projectile $\mathrm{H}$ ion) 

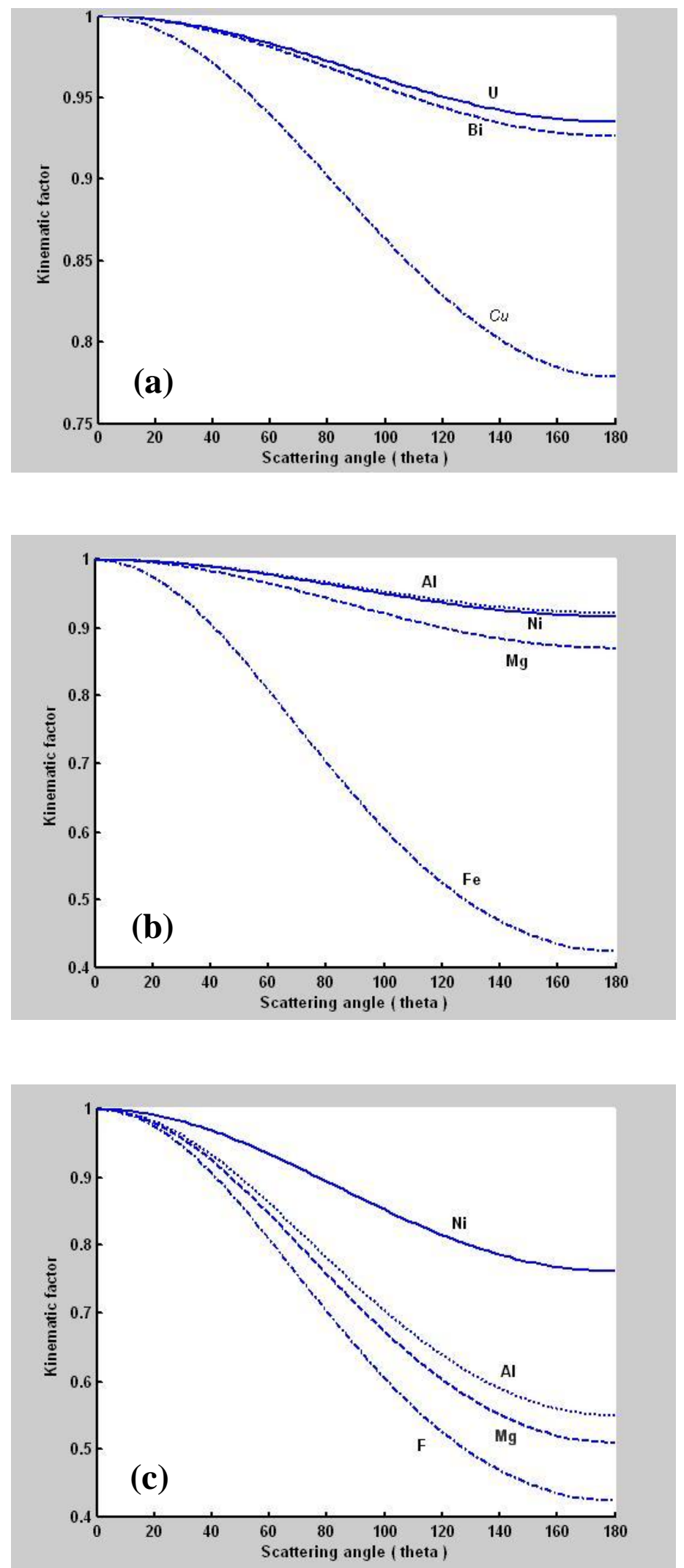

Fig (3): Kinematic factor as a function of scattering angles for different target elements (He ion projectile) 

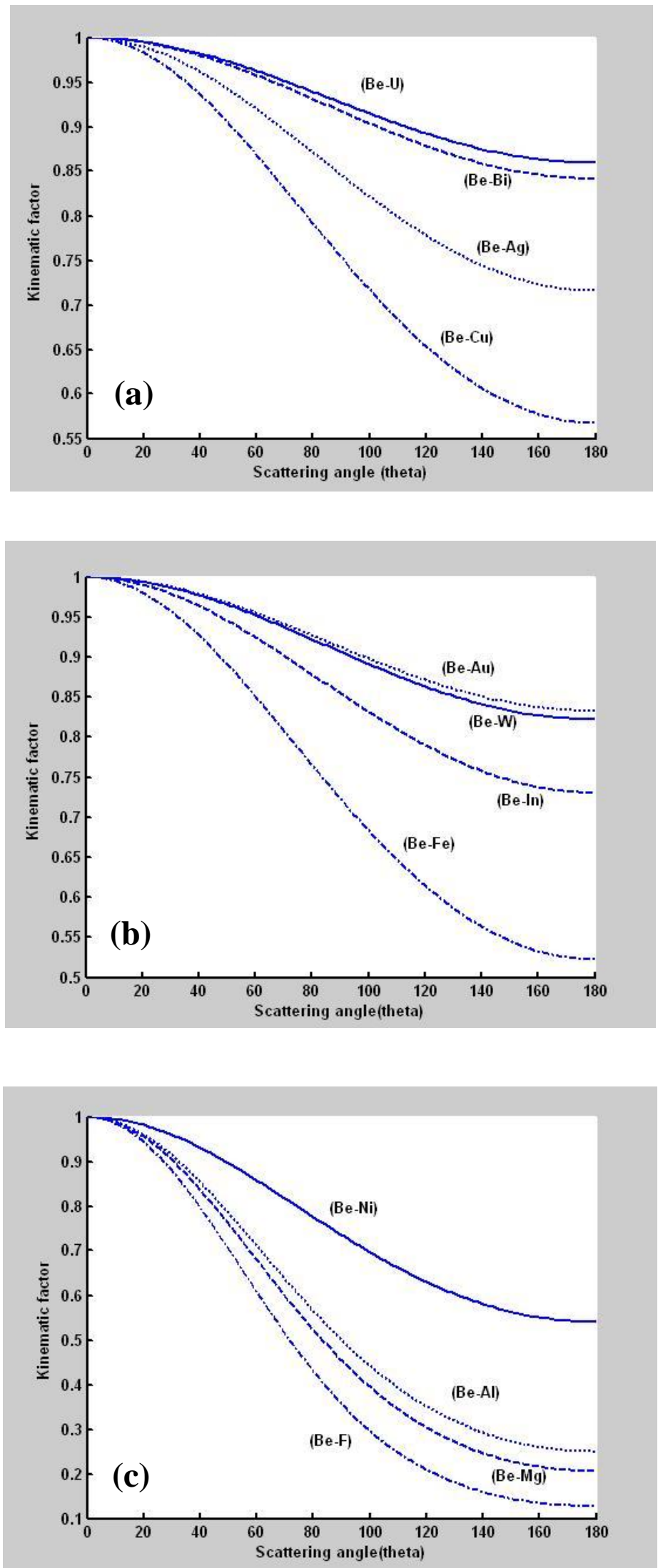

Fig (4) Kinematic factor as a function of scattering angle for different target elements (Be incident projectile) 

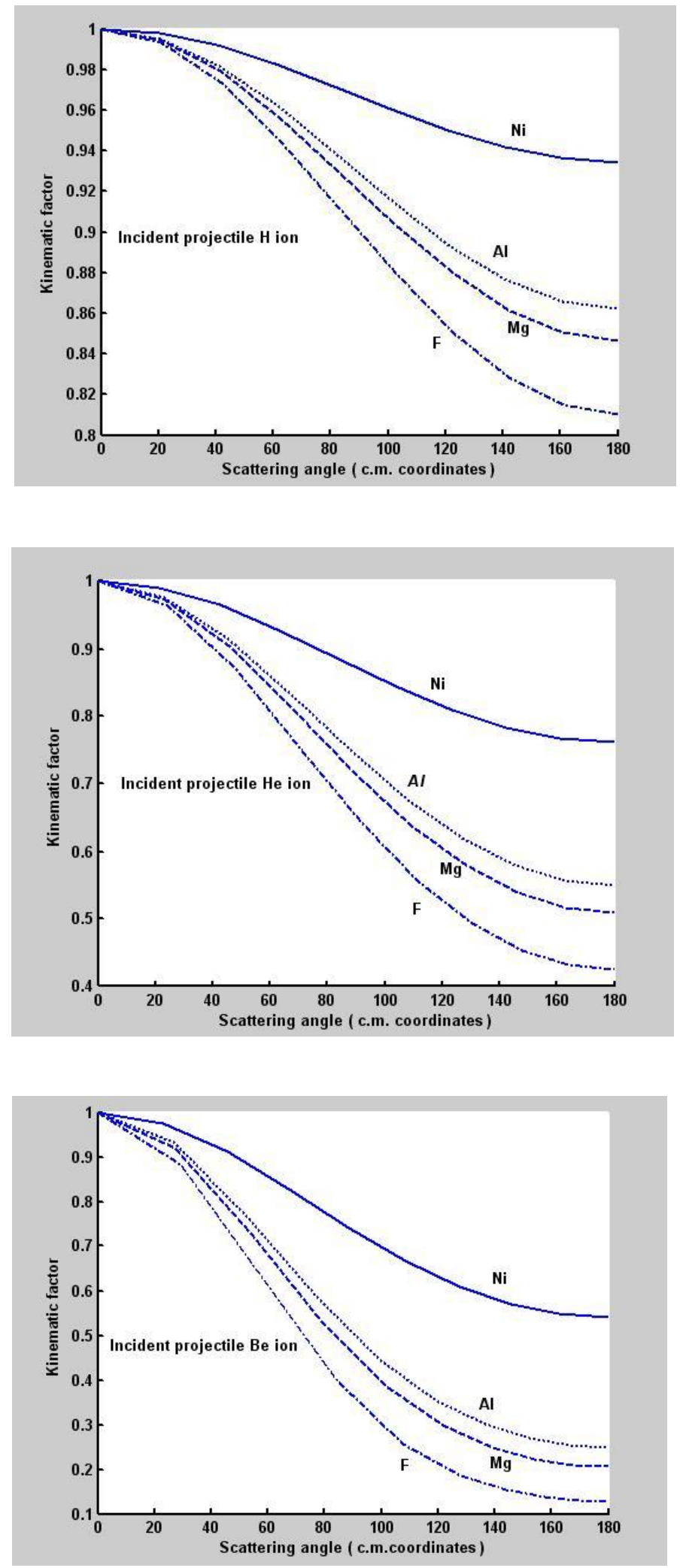

Fig (5): Kinemaic factor as a function of scattering angle (in c.m. coordinates) for different target elements through $(\mathrm{H}, \mathrm{He}$ and $\mathrm{Be}$ ions) as shown in in $(\mathbf{a}, \mathbf{b}$ and $c)$ 

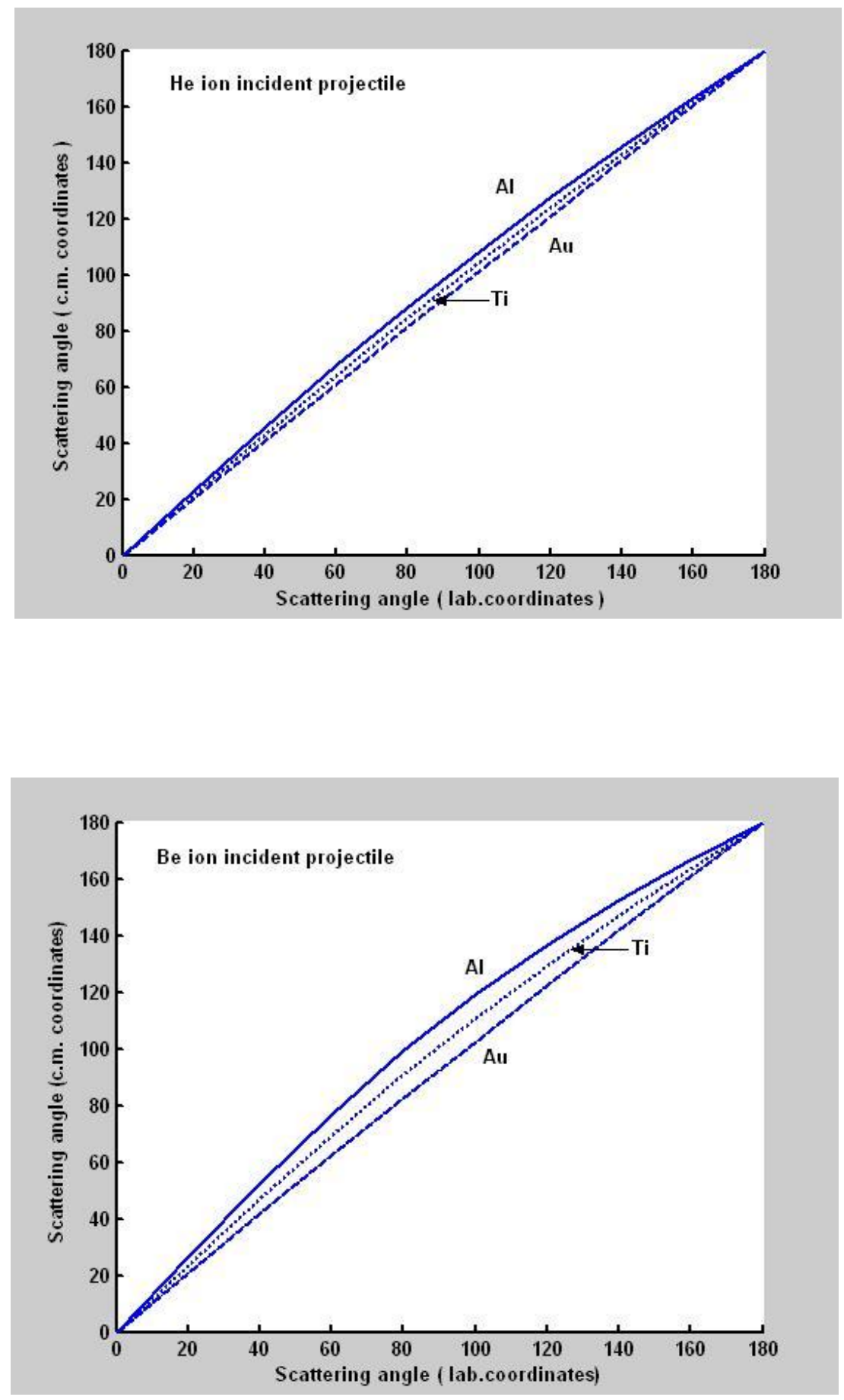

Fig (6): The relation between the scattering angles in the laboratoryof mass coordinates for target elements ( $\mathrm{Al}, \mathrm{Ti}$ and $\mathrm{Au}$ ) through the and incident projectiles (He and Be ions) as shown in (a and b) 


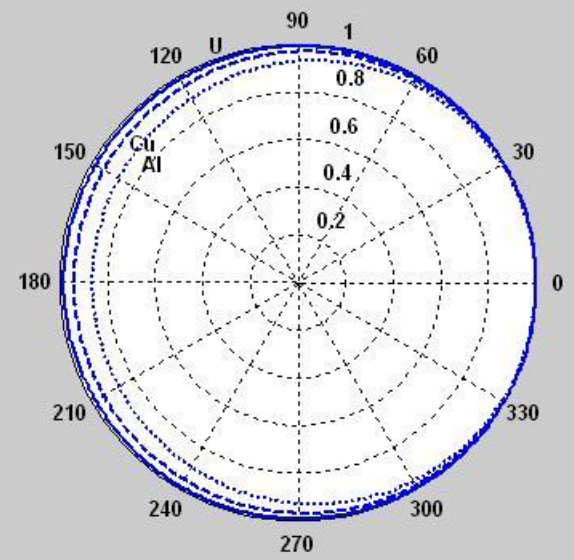

Projectile: He ion
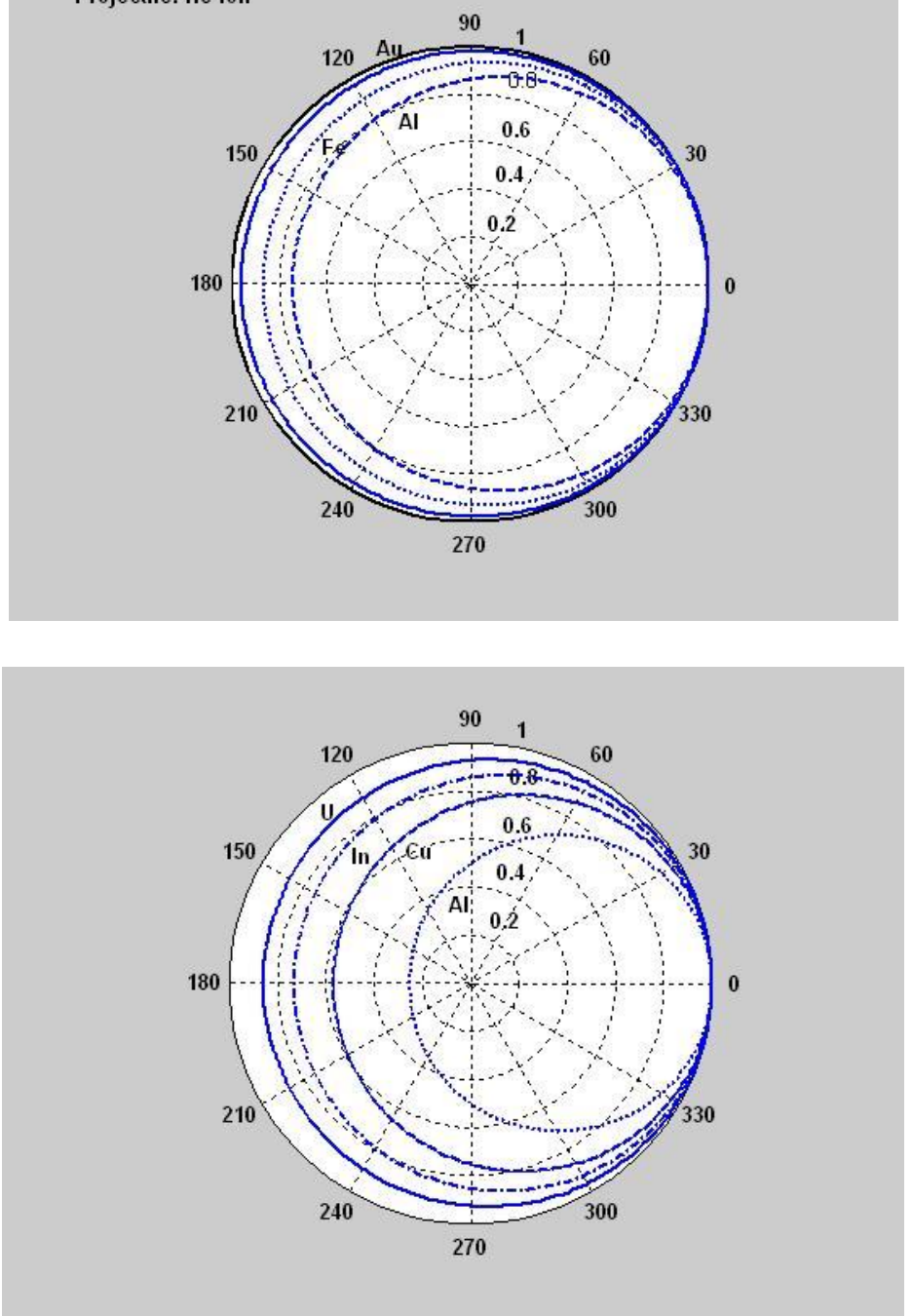

Fig (7): Polar plot of kinematic factor for different target elements through (H, He and Be) ions incident projectiles as shown in (a b and c) 

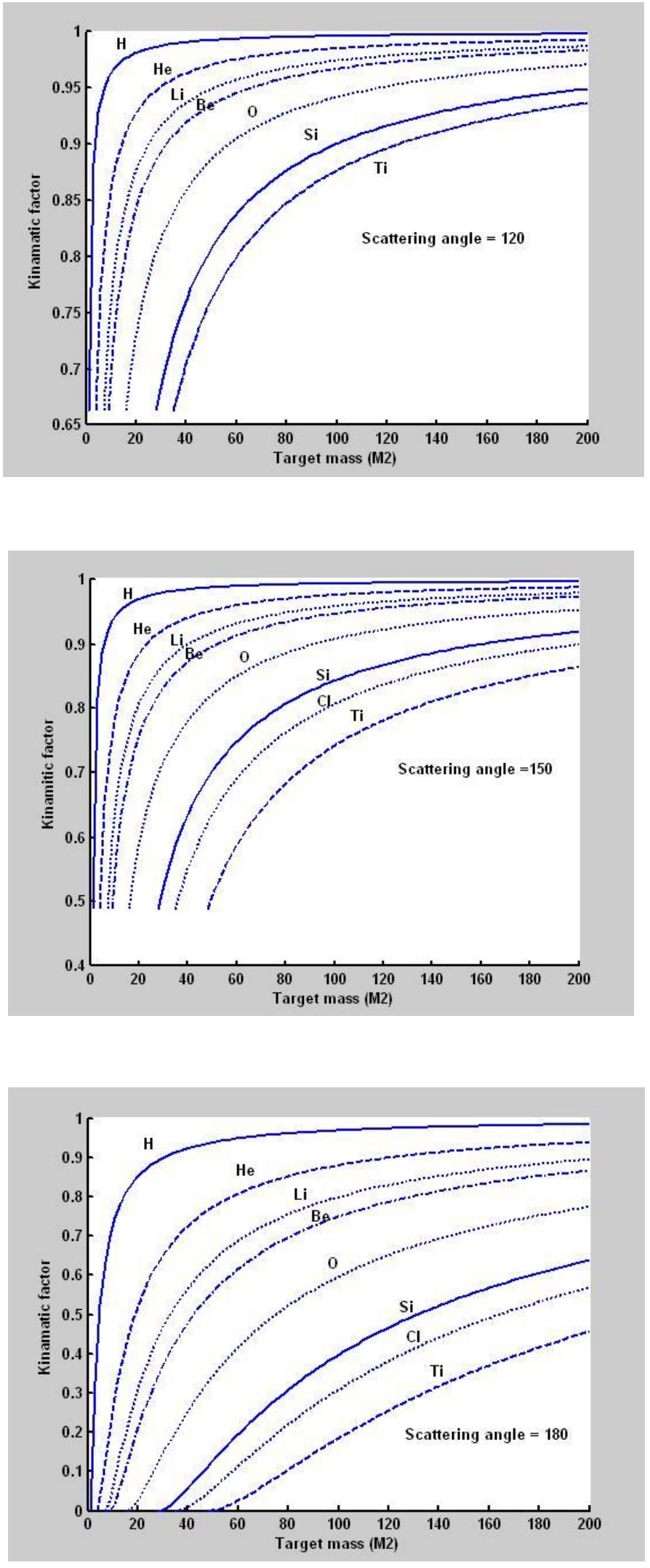

Fig (8): Kinematic factor as a function of target mass at three different scattering angles and for a number of incident projectile 


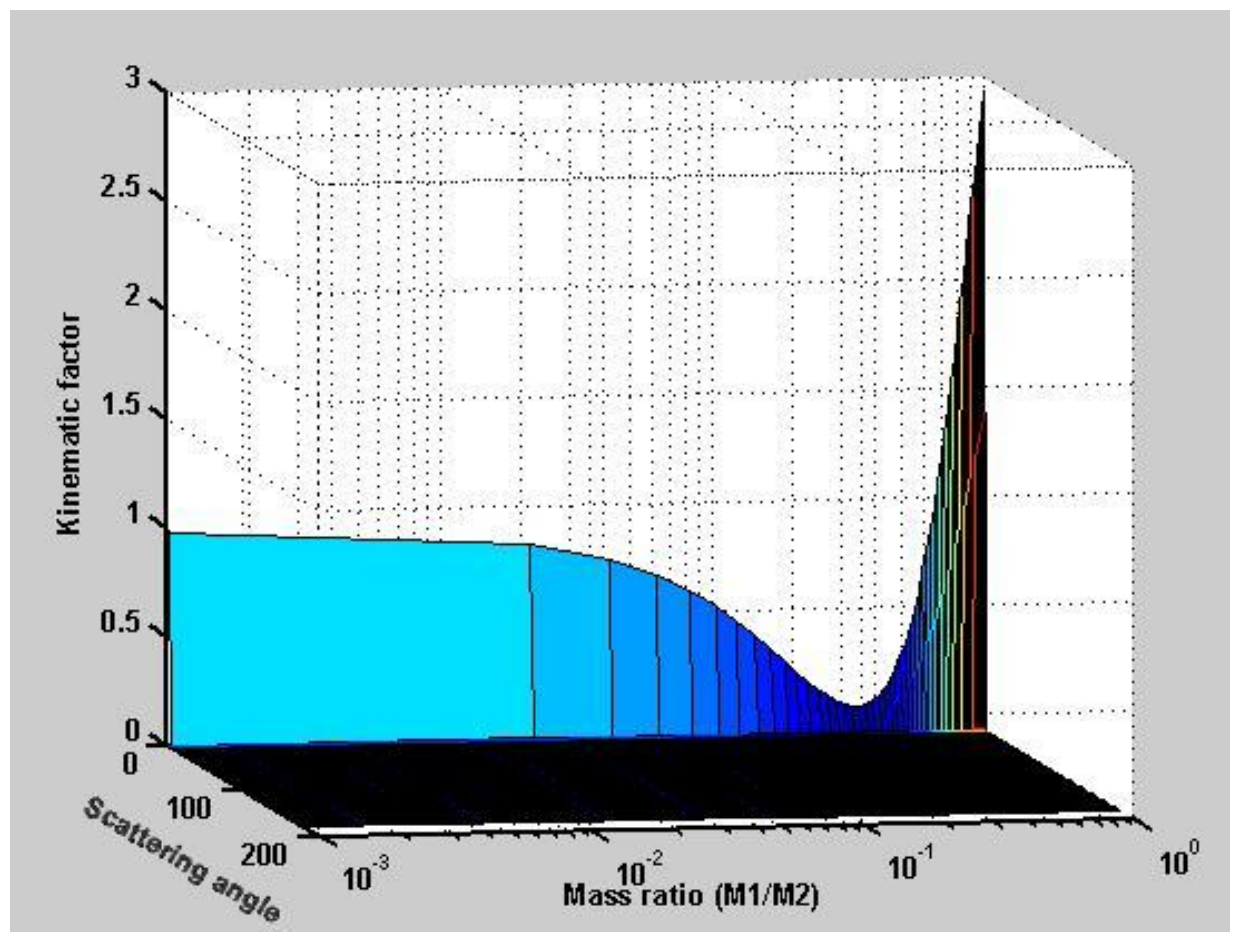

Fig (9): Surface plot of kinematic factor (E/Eo) dependence on the mass ratio(M1/M2) and the scattering angles (theta)

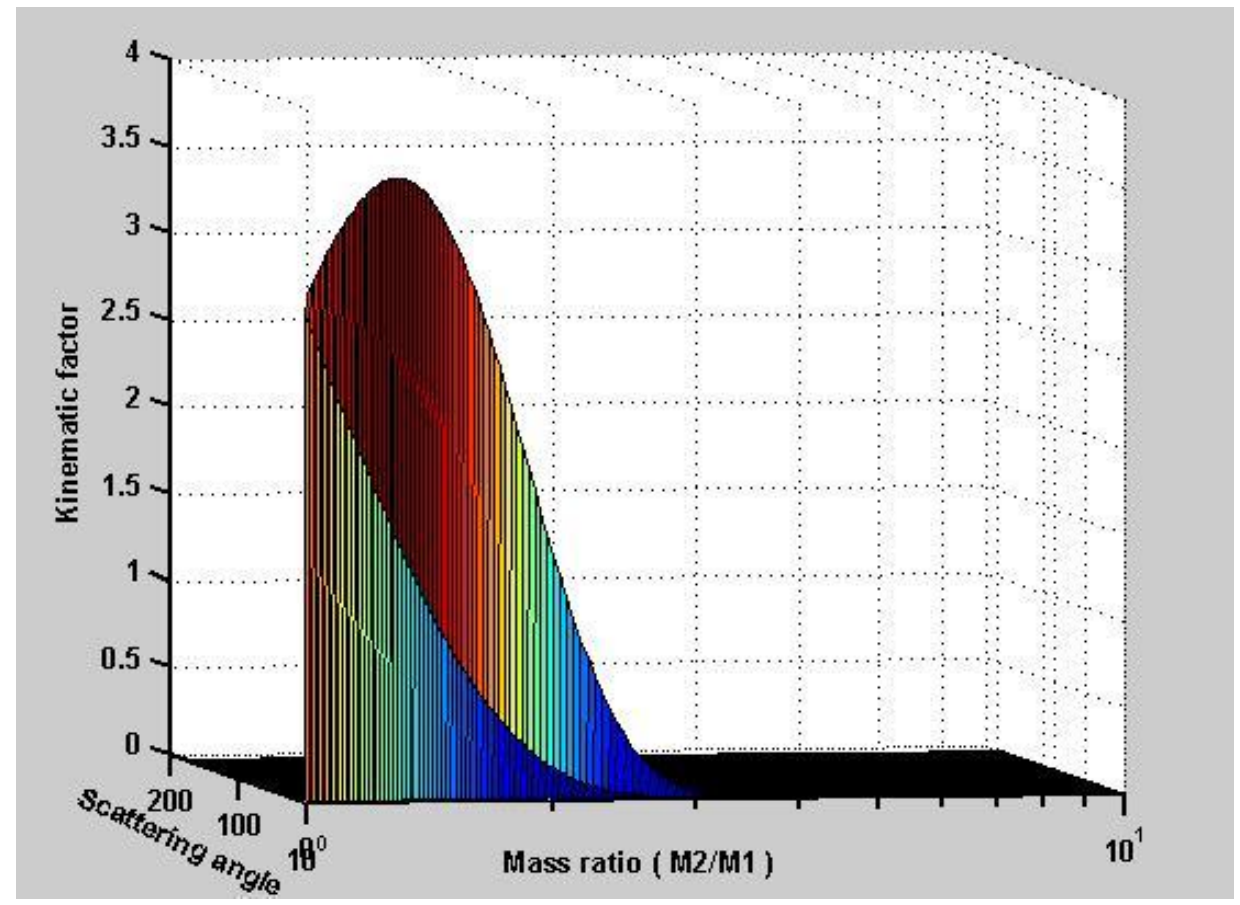

Fig (10): Surface plot of the kinematic factor(E/Eo) dependence on the mass ratio (M1/M2)and the scattering angles (theta) 

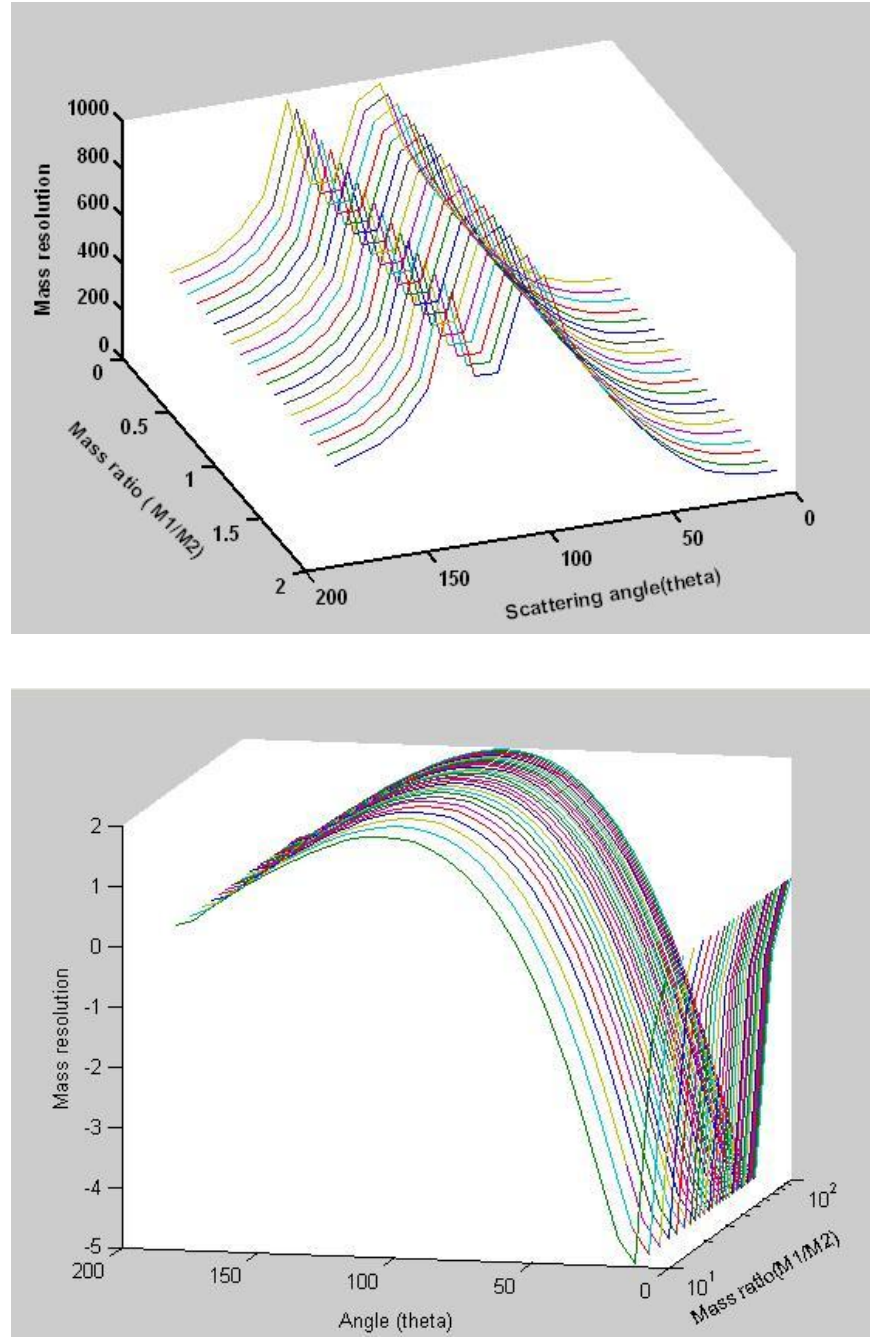

Fig (11): 3D plot of mass resolution $(M / \Delta M)$ as a function of mass ratio( $\left(M_{1} / M_{2}\right)$ and scattering angle (theta) for different mass ratio range as shown in $(a$ and $b)$

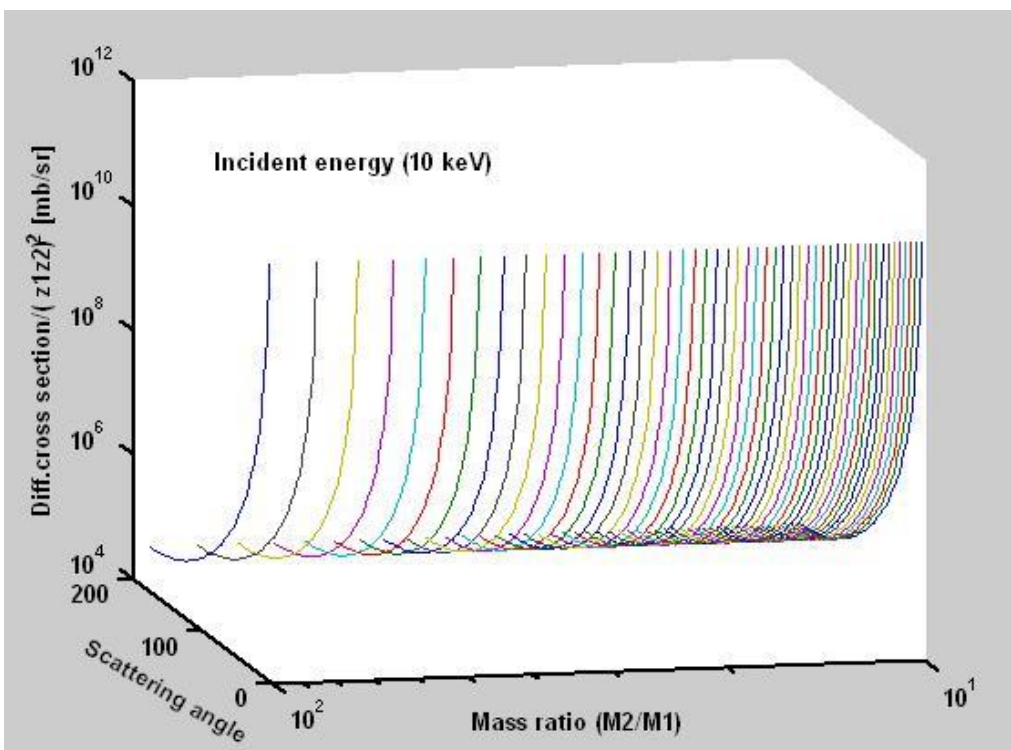

Fig (12): 3D plot of Rutherford differential cross section as a function Of mass ratio $\left(M_{2} / M_{1}\right)$ and scattering angles (theta) for incident energy $(10 \mathrm{keV})$ 

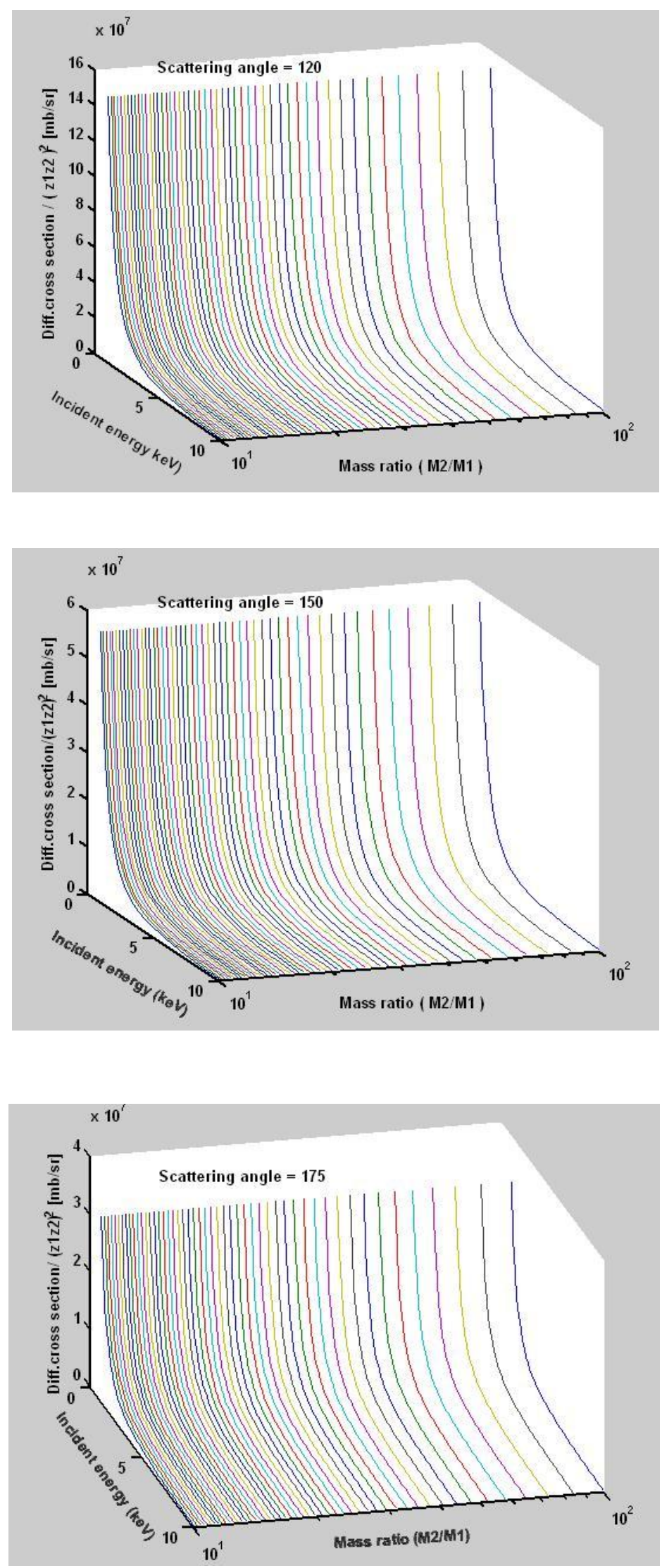

Fig (13): Differential cross section for backscattering dependence on the Mass ratio(M2/M1) and the incident energy for different scattering angles $(120,150$ and175) as shown in (a,b and c) 

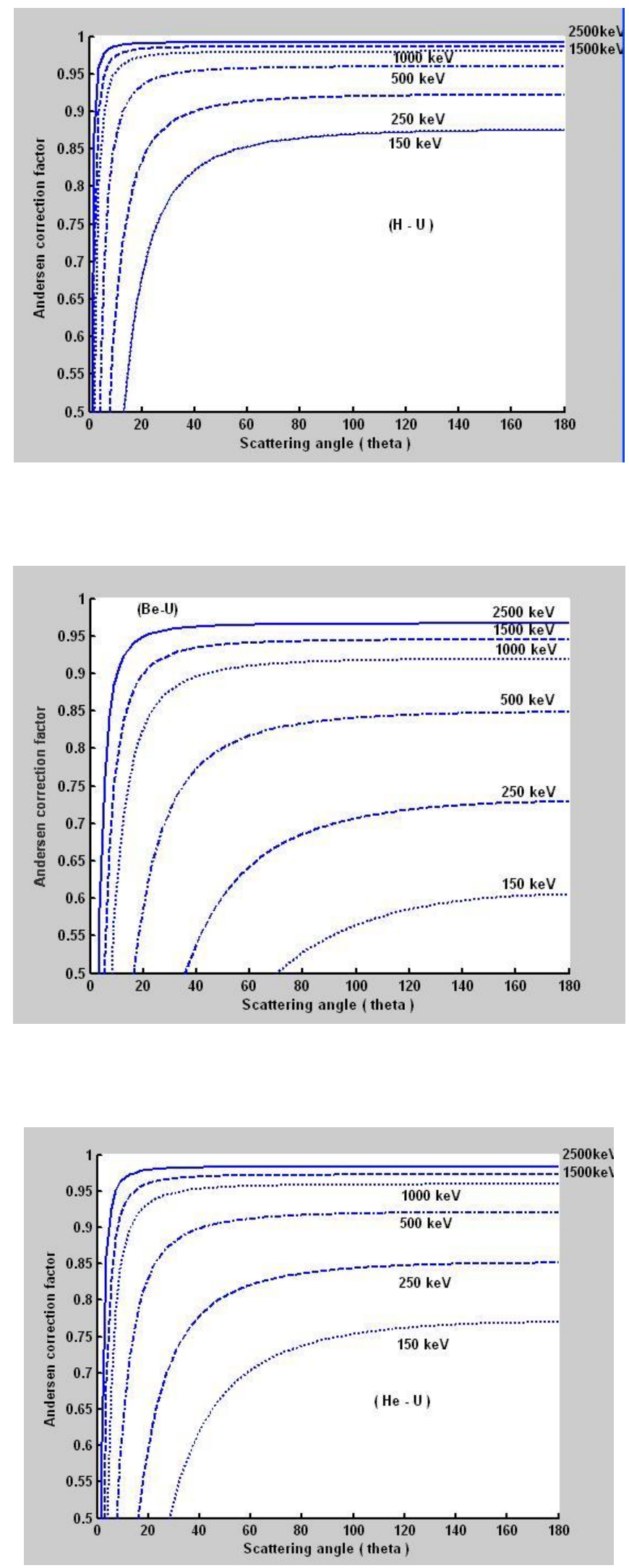

Fig (14): Andersen correction factor for Rutherford cross section as a function of scattering angles for $(\mathrm{H}, \mathrm{Be}$ and $\mathrm{He})$ projectiles backscattered from uranium at different energies as shown in (a,b and c) 

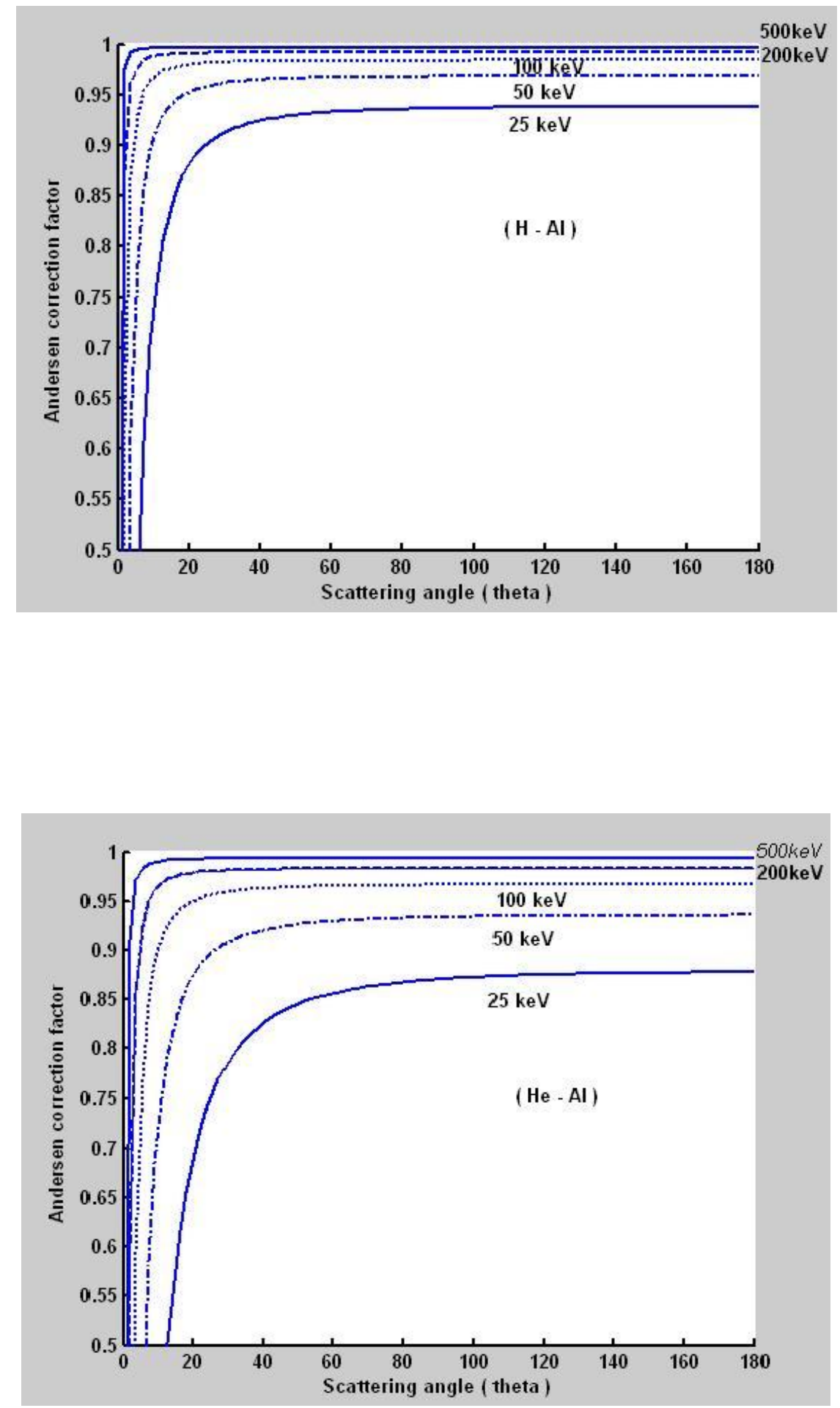

Fig (15): Andersen correction factor for Rutherford cross section as a function of scattering angles for $(\mathrm{H}$ and $\mathrm{He}$ ) projectiles backscattered from (Al at different energies as shown in (a and b 

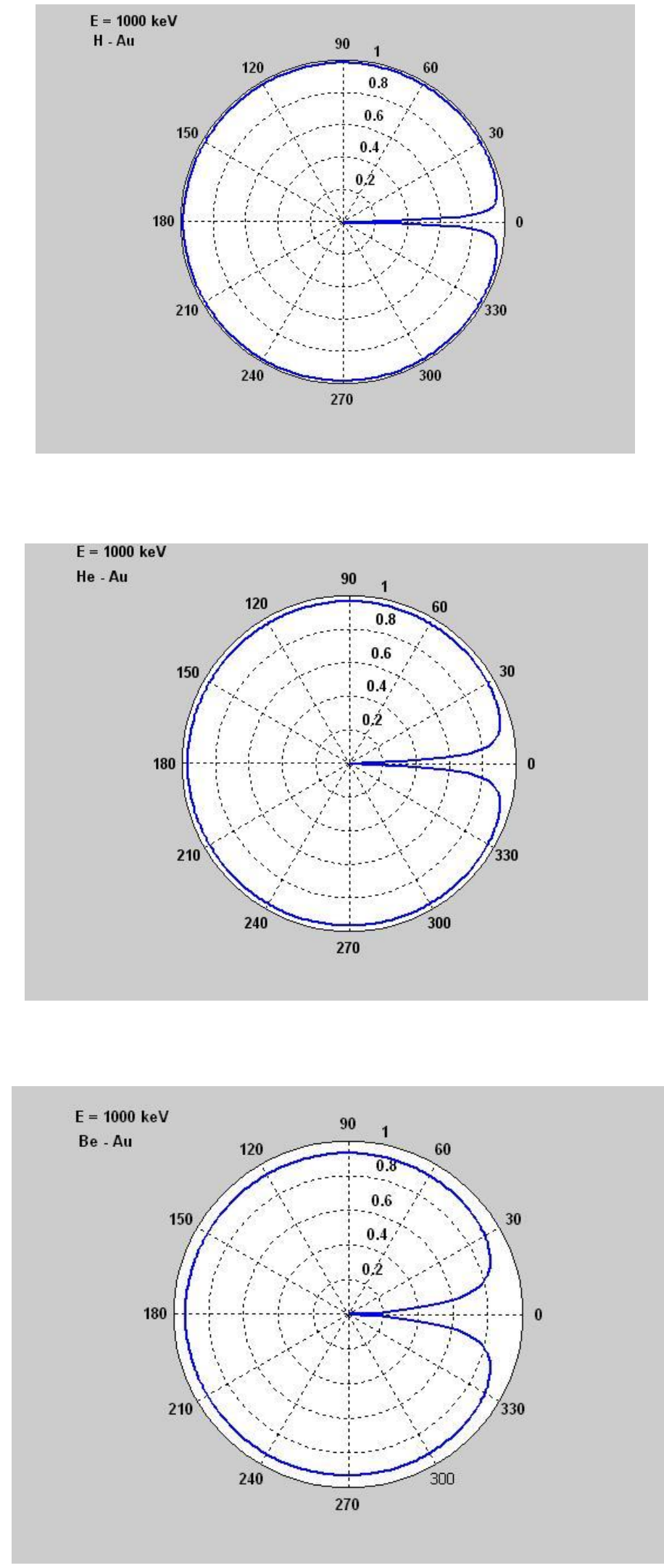

Fig (16): Polar plot of Andersen correction for Rutherford cross section for a target element ( $\mathrm{Au})$ and three different projectile ions $(\mathrm{H}, \mathrm{He}$ and $\mathrm{Be})$ as shown in (a, b, and c) 

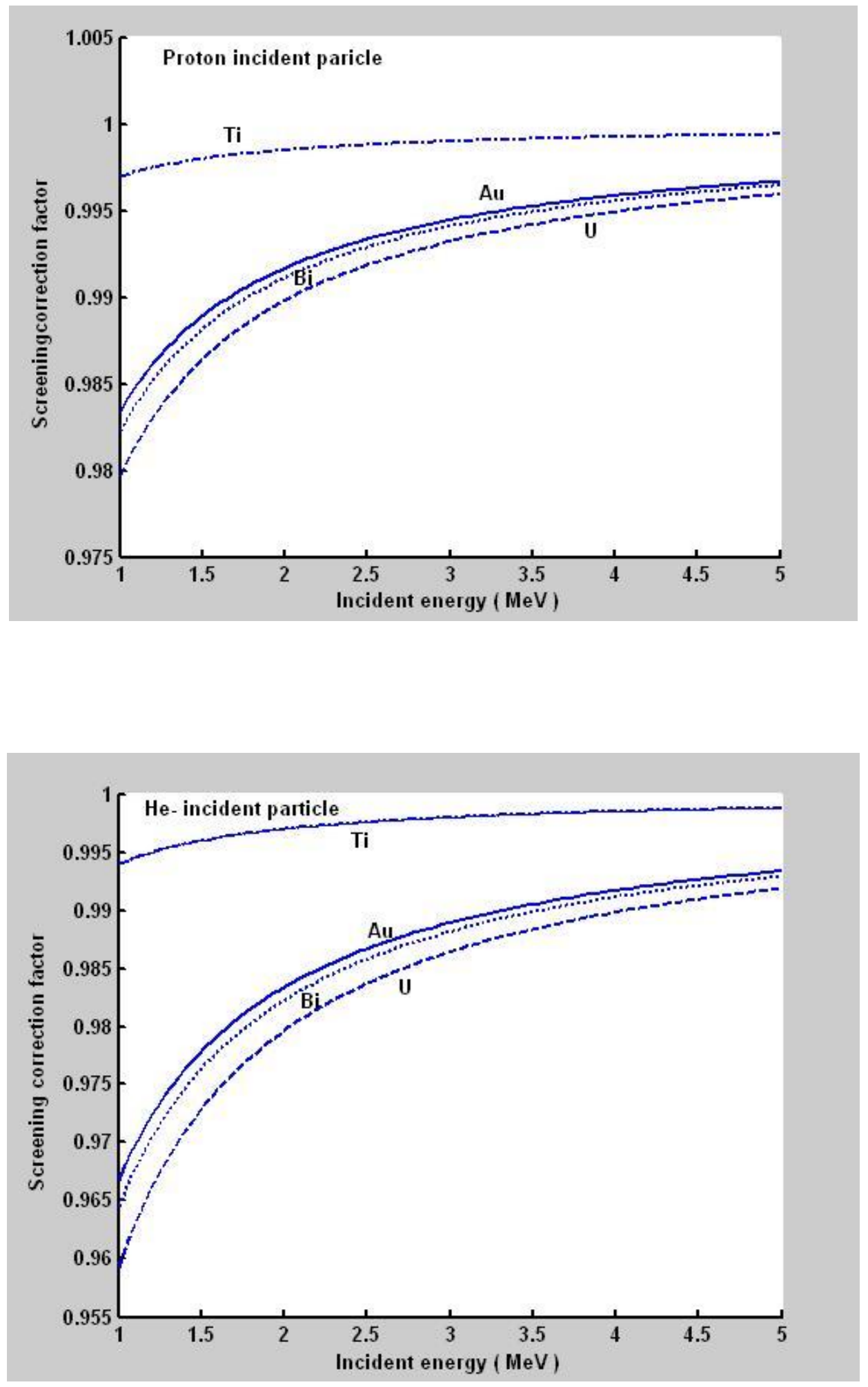

Fig (17): Screening correction function of incident energy factor as a for a target elements ( $\mathrm{Ti}, \mathrm{Au}, \mathrm{Bi}$ and $\mathrm{U}$ ) through incident ions ( $\mathrm{H}$ and $\mathrm{He}$ ) as shown in (a and b) 


\section{Conclusion:}

Quantitative analysis with ion beam analysis techniques are based on the knowledge of the interaction cross section.

In material science with ion beam of the elemental, quantitave analysis of the studied sample are the main goal. A detailed studies had been done in this work for the important parameters, such as $\mathrm{k}$ factor, mass resolution, differential cross section of the backscattering of the atoms, in addition to correction factors for cross section due to the nuclear charges combinations,

scattering angles and mass ratio have been performed. Moreover the simulation of these parameters had been done through the three dimensional and surface plots.

\section{Acknowledgment:}

I would to thank Dr. M. I. Azawi in physics department - College of Eduction -Mosul University for his helpful and discussion.

\section{References:}

1) E. Rutherford, (1911), Phil. Mag., 21, 669

2) Chu, W. K., Mayer, J. W., Nicolt, (1978) Back scattering Spectrometry, Academic press.

3) Nakles, M.R, Experimental and modeling studies of low energy ion Sputtering for ion thrusters, thesis submitted to the Faculty of Virginia polytechnics institute for master science, july 2004, Blackburg, Virginia.

4) Jalkanen, P, Properties of sige alloys studied by ion beam and Suppression of Al film superconductivity by implantation, Ph.D Thesis, University of Jyvaskyla, March 92007.

5) Martin, J.W, Yuan, J, Hoedi, S. A, Filippone, B.W, Fong, D, Ito, T.M, Lin, E, Tipton, B and Yang, A.R, Phys. Rev.c 68055503 (2003).

6) Dobeli, M. Cas. web. cem. ch / cas / pruhonice / PDF / Doebli. pdf.

7) Mayer, M. (2003) Users. ictp. It / pub - off / lectures / inso2z /Mayer - 1 .

8) Chourasia, A.R and Chopra, D. R. www. poenhall. com / settle / chapers / ch42.pdf

9) Takagi, I., Sasaki, T., Asahara, Kausak, T. Ishidera and Moriyoma, H., (2004), J. of nuclear science and techonology, 41, 8, p837.

10) Martin, J. W., Yuan, J., Hoedi, S. A, Filipone, B. W., Fong, D., Ito, T.M., Lin, E., Tipton, B., and Young, A. R., (2003), Physical Review c 68.055503.

11) Hage - Ali, M., Siffer, P.S., (1981), Review Phys. Appl.,165 - 172. 